\title{
A NOTE ON CHANGES IN BLACK RACIAL
}

\section{ATTITUDES IN DETROIT : $1968-1976^{*}$}

Of all the urban riots of the late sixties in the United States, the largest occurred in Detroit in July, 1967. Ten months later the University of Michigan's Detroit Area Study carried out a sample interview survey of the Black adult population of Detroit and included a number of questions designed to assess the alienation of Blacks from White institutions and from Whites in general. A number of these questions were repeated in a new survey in 1971, and the results showed a sharp rise in Black alienation over the three year period. For whatever reason, the immediate postriot period saw an increase in Black feelings of distrust toward Whites, rejection of contact with Whites, and endorsement of violence as perhaps the only way to gain equal rights. ${ }^{1}$

Five of the key questions from the earlier surveys were repeated again in 1976 - five years after the last study, eight years after the initial one, and nine years after the riot itself. For comparison purposes, only the responses of Black heads and spouses of heads of household, ages 21 to 69 and living in the city of Detroit, are reported here. The need to equate the three samples resulted in the following sample sizes: 339 in 1976, 208 in 1971, and 417 in 1968. ${ }^{2}$

A comparison of the new findings with those from 1971 reveals a notable turnabout: on almost all items, Black alienation has dropped from the relatively high levels of 1971 back to the immediate 1968 post-riot levels. Thus, willingness to use violence to obtain equal rights had gone from endorsement by six percent of the Black population in 1967 up to $11 \%$ in 1971, but dropped to four percent in 1976. The proportion of Blacks trusting no White people rose from 10 percent to 16 percent between 1968 and 1971, but fell back to 10 percent in 1976. On the issue of residential preference, the percentage desiring to live in essentially all-Black neighborhoods moved from $12 \%$ in 1968 to $19 \%$ in 1971 , then dropped to $11 \%$ in 1976.

All three of these changes are statistically reliable $(p<.05$, using chi square tests), and the overall trends are unmistakable. However, closer examination of the data does reveal some important qualifications. A fourth ques- 


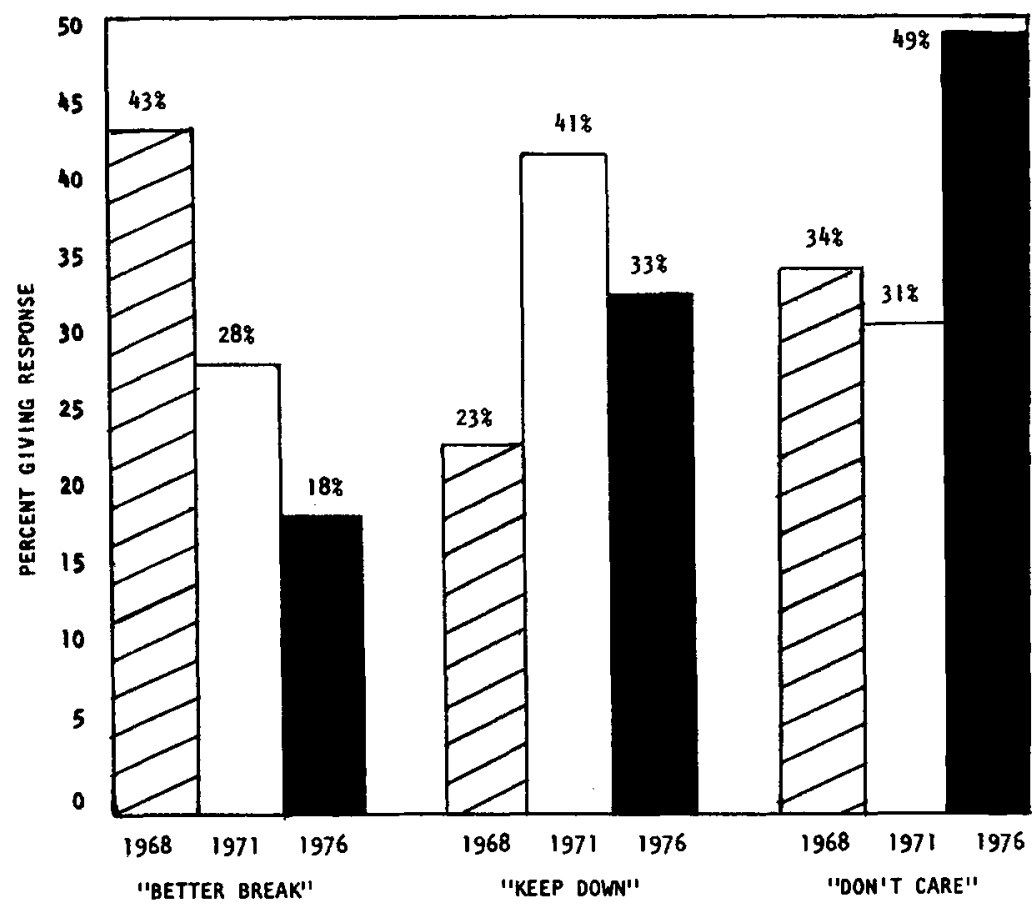

Figure 1. QUESTION: On the whole, do you think most White people in Detroit want: 1. To see Blacks get a better break, 2. Or do they want to keep Blacks down, 3. Or don't they care one way or the other?

tion dealing with Black perceptions of the intentions of most Whites provided three alternatives: Whites want to "keep Blacks down," Whites want to give Blacks "a better break," and Whites "don't care" about Blacks one way or another. While it is true that beliefs about deliberate White repression ("keep down") dropped 8\% from 1971 to 1976 , beliefs that Whites want to help Blacks get ahead also dropped by $10 \%$. (See Figure 1.) What rose - by a remarkable $18 \%$ - was the response "White's don't care one way or the other." (Looked at another way, the most common response in 1968 was "better break"; 1971 it was "keep down"; and by 1976 it was "don't care".) Thus, the main perception today by Blacks is that Whites are indifferent to Black advancement, rather than being either helpful or harmful.

A fifth question repeated from the 1968 and 1971 surveys is the only one that fails to show significant change, and in fact it shows a trend opposite 
to most of those reported thus far. Black respondents were five percent less likely in 1976 to perceive "a lot of progress in getting rid of racial discrimination" over the "last ten or fifteen years" than they were in 1971, and $10 \%$ less likely than in 1968. This was probably a realistic change, for the more dramatic federal actions for civil rights, whether Executive, Congressional, or Court, occurred in the 1950's and early 1960's, and by 1976 were becoming events of history, not of the immediate present. The different trend on this question suggests that Black attitudes and beliefs are too complex to be neatly placed on a single dimension such as "militant/non-militant."3

Our 1976 study also replicated three items originally asked in a 1968 Survey Research Center study, though these had not been repeated in $1971 .^{4}$ The items attempted to measure support for three aspects of "Black consciousness" - economic self-determinism, social separatism, and cultural identification. The shifts found from 1968 to 1976 for these items add further complexity to the picture of Black racial attitude change. While support for shopping only in Black-owned stores decreased from $62 \%$ in 1968 to $52 \%$ in $1976(\mathrm{p}<.01)$, agreement with the statement that "Black school children should study an African language" rose from 33\% to 55\% over the same period $(\mathrm{p}<.01)$. (An item about Blacks avoiding Whites as much as possible showed no change: Blacks overwhelmingly disagreed [93\%] with this item in both years.) In sum, the overall decline in feelings of distrust toward Whites was accompanied by an increase in the cultural aspect of Black consciousness.

Any comparison of surveys taken at different points must be careful that apparent changes over time are not in fact due to differences in the ways the surveys were conducted. Precautions were taken in both 1971 and 1976 to make comparisons to 1968 as exact as possible. The same organization, the Detroit Area Study, was responsible for all three studies. Black interviewers graduate students in Sociology and Survey Research Center professional interviewers - gathered all the data now being reported. The basic method of area probability sampling was the same in all three studies, and minor differences have been taken into account in making the calculations presented here.

There is one difference between 1971 and 1976 , however, that is more difficulat to deal with: whereas about $80 \%$ of the intended respondents were actually interviewed in both 1968 and 1971, in 1976 this rate of interviewing (like that of most other urban suveys) had dropped noticeably - by nearly 
$10 \%$ for the Black sample. It is conceivable that the drop is accounted for by the refusal of the most alienated Blacks in Detroit to take part in the more recent survey. However, while there is anecdotal evidence to suggest that a few such cases may have occurred, our best estimate is that the drop in response rate is not an important factor in the attitude changes reported earlier. For one thing, the response rate was not different for the 1976 Detroit Area Study than for the other urban surveys today, so that refusals were probably seldom in reaction to the contents of this particular survey. Moreover, much impressionistic evidence indicates that the increase in urban refusals is largely due to fear of crime and other hazards in opening doors to strangers. Finally, a more direct approach to the response rate problem is to ask whether the 1976 survey underrepresented parts of the population that were particularly high in alienation in 1971. Comparisons of the 1971 and 1976 data show little difference in terms of age or sex, which were the main demographic correlates of alienation responses in the earlier surveys. Thus it is unlikely that the changes in answers to racial questions between 1971 and 1976 can be explained by changes in what parts of the population were interviewed.

There are four other points that need to be kept in mind when interpreting Black attitude changes between 1968 and 1971. First, the data reported here concern Detroit and may be influenced by special features of that city (for example, the rise to majority status there of Blacks). Despite this caution, it is probable that changes registered in Detroit are reflective of changes in the nation more generally, especially among Blacks in other large urban areas of the United States. Second, the present report deals only with attitudes of Blacks toward Whites and toward race relations more generally. It is possible that in other spheres of life, for example, trust in conventional political forces, no change or entirely different changes have occurred. Indeed, even within the racial sphere, we have seen that while the dominant trend appears to be a drop in Black alienation, other items show different but equally meaningful patterns. Black racial attitudes obviously do not constitute a single dimension, and it is only because our surveys included a wide range of items that an adequate picture of change begins to emerge.

Third, the drop in signs of Black alienation since 1971 leaves it high in more absolute terms on some questions. Thus a third of the sample in 1976 still feels that most Whites are trying to keep Blacks down. Finally, it is tempting but often incorrect to assume that recent trends will be carried 
forward into the future. Just as Black alienation has changed in direction over the three studies reported here, it can change again depending on larger social events. Indeed, without the intervening 1971 measurement point, we would not have realized the sharp rise and fall along certain dimensions of Black attitudes between 1968 and 1976 .

\section{University of Michigan}

\section{NOTES}

* The authors share equal responsibility for this report, and are also indebted to Suzanne Bianchi and Diane Colasanto who collaborated on the larger project of which this was one part. The research was supported by a grant (SOC76-00768) from the National Science Foundation to Reynolds Farley, and was carried out through the University of Michigan's Detroit Area Study.

1 Changes from 1968 to 1971 were reported in Duncan, Schuman, and Duncan (1973), and later analyzed in detail in Schuman and Hatchett (1974). The main items discussed in this report are printed in both these sources.

2 For a description of the 1976 sampling procedure and results, see Bianchi, 1976. Sampling for other surveys discussed here is described in Schuman and Hatchett, 1974.

3 One other item from this $1968-1971$ series was repeated in 1976, but it is more ambiguous in meaning. Significantly fewer Blacks in 1976 than in 1971 believed there to be discriminatory treatment of Blacks shopping in downtown department stores, but since the sales staffs of these department stores have also become more heavily Black in composition, the change in belief is not entirely clear in interpretation.

4 See Campbell and Schuman, 1968, for a description of this 1968 survey and of these items. Although that survey covered 15 American cities, only the Detroit data were used for the present comparison.

\section{REFERENCES}

Bianchi, Suzanne M. 1976, 'Sampling Report for the 1976 Detroit Area Study', Unpublished paper, Detroit Area Study, University of Michigan.

Campbell, Angus and Schuman, Howard. 1968, 'Racial Attitudes in Fifteen American Cities'. In Supplemental Studies for the National Advisory Commission on Civil Disorders, Washington: U.S. Government Printing Office.

Duncan, Otis Dudley, Schuman, Howard, and Duncan, Beverly. 1973, Social Change in a Metropolitan Community, Russell Sage Foundation.

Schuman, Howard and Hatchett, Shirley. 1974, Black Racial Attitudes: Trends and Compexities, Ann Arbor: Institute for Social Research. 